\title{
EQUILIBRIUM RELATIONS IN Mg-RICH PART OF THE PYROXENE QUADRILATERAL
}

\author{
YASUO NAKAMURA \\ Geological Institute, Faculty of Science \\ University of Tokyo, Hongo, Tokyo, Japan
}

\begin{abstract}
Coexisting inverted protoenstatite and bronzite from Cape Vogel, Papua (Dalwitz, Green \& Thompson, 1966) were re-examined to obtain partition coefficient of $\mathrm{Mg}$ and $\mathrm{Fe}$ between contiguous protopyroxene and orthopyroxene. Stability relations of pyroxenes in the system $\mathrm{MgSiO}_{3}-\mathrm{FeSiO}_{8}$ are suggested mainly on the basis of the partition coefficients of $\mathrm{Mg}$ and $\mathrm{Fe}$ between natural coexisting protopyroxene and orthopyroxene and between natural coexisting orthopyroxene and Ca-poor clinopyroxene. The most probable isothermal sections in the $\mathrm{Mg}$-rich part of the ternary system $\mathrm{CaSiO}_{3}-\mathrm{MgSiO}_{8} \cdot \mathrm{FeSiO}_{3}$ are presented.
\end{abstract}

\section{Introduction}

Several detailed petrographical works with the use of microprobe (e.g., Dalwitz, Green \& Thompson, 1966; Nakamura \& Kushiro, 1970a, b) have contributed to the understanding of the equilibrium relations of natural pyroxenes. Extensive microprobe studies on lunar pyroxenes by many authors have also cast new light on the phase equilibria in the pyroxene quadrilateral. The purpose of the present paper is to construct most probable hypothetical phase diagrams in the Mg-rich part of the quadrilateral, which are consistent with the compositional and textural relations of natural pyroxenes and with experimental data on the pyroxene systems. The presented phase diagrams are chiefly concerned with crystallization of pyroxenes in basaltic and andesitic magmas. 
Re-examination of inverted protoenstatite from Cape Vogel, Papua and stability field of protopyroxene

Dalwitz, Green \& Thompson (1966) described twinned clinoenstatite phenocryst together with bronzite phenocryst, and concluded that the twinned clinoenstatite was originally protoenstatite at the time of its crystallization from magma. The clinoenstatite in the Cape Vogel andesite is poorer in $\mathrm{Ca}$ than the coexisting bronzite. This fact strongly supports the interpretation by Dalwitz, Green \& Thompson because this compositional relationship is the same as that in the experimental studies in the system enstatite-diopside by Atlas (1952) and Boyd \& Schairer (1964). Sadanaga \& Okamura (1969) studied morphologically the clinoenstatite phenocryst from Cape Vogel and demonstrated that its outer form has orthorhombic symmetry. They also found that axial ratio determined from the morphological study is in good agreement with that determined from the high temperature X-ray diffraction data on synthetic protoenstatite at $1,100^{\circ} \mathrm{C}$. From these studies, little doubt seems to exist on the conclusion that the clinoenstatite phenocryst in the Cape Vogel andesite crystallized originally as protoenstatite.

Pyroxenes in the Cape Vogel andesite were briefly re-examined in this study in order to obtain partition coefficient of $\mathrm{Mg}$ and $\mathrm{Fe}$ between two different pyroxenes coexisting together in equilibrium. The rock used for the present study is a clinoenstatite andesite (specimen No. B9) which was collected at 3 miles from Magabara, Cape Vogel Peninsula and supplied by Dr. W. B. Dalwitz to the late Professor H. Kuno. Thirteen complete analyses were made on the pyroxenes with electron probe microanalyzer. The compositions of contiguous protopyroxene and orthopyroxene less than $20 \mu \mathrm{m}$ apart from each other were determined. JEOL electron probe microanalyzer Model JXA-5 was used. Analytical procedures are the same as those described by Nakamura \& Kushiro (1970a) and Kushiro \& Nakamura (1970). Fig. 1 shows sketches of the analyzed contiguous pyroxene pairs. In grain Nos. 2 and 8, bronzite crystal is partly included in inverted protopyroxene crystal, 
No.2

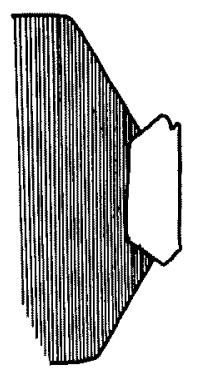

No.7
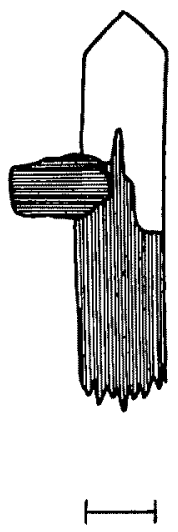

$0.1 \mathrm{~mm}$
No.8

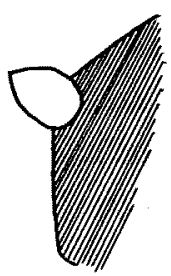

Fig. 1. Sketches of analyzed grains of inverted protoenstatite (shaded) and bronzite (clear) which occur as contiguous crystals.

whereas grain No. 7 is a composite grain. These textures would indicate that the contacting parts of these pyroxenes were in equilibrium when they crystallized. The selected analytical results are given in Table 1 and all are plotted in Fig. 2 together with data by Dalwitz, Green \& Thompson (1966).

Orthopyroxene is richer in $\mathrm{Fe}, \mathrm{Ca}$ and $\mathrm{Al}$ than protopyroxene as. have already been shown by Dalwitz, Green \& Thompson. In addition, it is clear that orthopyroxene contains more $\mathrm{Mn}$ and $\mathrm{Ti}$ than protopyroxene, although the differences are very small. Both the pyroxenes: contain considerable amounts of $\mathrm{Cr}_{2} \mathrm{O}_{3}(0.4 \sim 0.6 \mathrm{wt} \%)$ and $\mathrm{NiO}(0.05 \sim$ $0.13 \mathrm{wt} \%$ ). It is not clear, however, which pyroxene prefers $\mathrm{Ni}$ and $\mathrm{Cr}$.

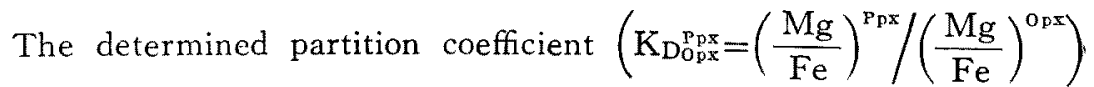

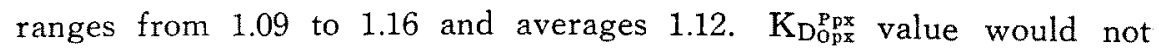
change much in the Ca-free system at temperatures above $1,000^{\circ} \mathrm{C}$. 
Table 1. Electron probe analyses of contiguous protoenstatite and bronzite.

\begin{tabular}{l|c|c|c|c|c|c}
\hline Grain No. & \multicolumn{2}{|c|}{2} & \multicolumn{2}{c|}{7} & \multicolumn{2}{c}{8} \\
\hline $\begin{array}{l}\text { Point of } \\
\text { Analysis }\end{array}$ & $2-2$ & $2-3$ & $7-1$ & $7-2$ & $8-2$ & $8-3$ \\
\cline { 2 - 7 } & $\mathrm{Ppx}$ & $\mathrm{Opx}$ & $\mathrm{Ppx}$ & $\mathrm{Opx}$ & $\mathrm{Ppx}$ & $\mathrm{Opx}$ \\
\hline $\mathrm{SiO}_{2}$ & 56.9 & 56.5 & 57.5 & 56.5 & 56.8 & 56.2 \\
$\mathrm{Al}_{2} \mathrm{O}_{3}$ & 0.59 & 0.69 & 0.63 & 0.71 & 0.71 & 0.62 \\
$\mathrm{TiO}_{2}$ & 0.02 & 0.04 & 0.02 & 0.03 & 0.03 & 0.03 \\
$\mathrm{Cr}_{2} \mathrm{O}_{3}$ & 0.45 & 0.41 & 0.45 & 0.53 & 0.41 & 0.36 \\
$\mathrm{FeO}$ & 8.17 & 8.72 & 7.97 & 8.71 & 8.29 & 9.20 \\
$\mathrm{MnO}$ & 0.16 & 0.19 & 0.15 & 0.17 & 0.15 & 0.18 \\
$\mathrm{NiO}$ & 0.08 & 0.10 & 0.12 & 0.08 & 0.10 & 0.07 \\
$\mathrm{MgO}$ & 33.9 & 33.1 & 34.1 & 33.3 & 34.3 & 32.9 \\
$\mathrm{CaO}$ & 0.36 & 0.70 & 0.34 & 0.74 & 0.31 & 0.80 \\
$\mathrm{Na} \mathrm{O}_{2} \mathrm{O}$ & 0.02 & 0.02 & 0.02 & 0.03 & 0.01 & 0.02 \\
$\mathrm{Total}$ & 100.7 & 100.5 & 101.3 & 100.8 & 101.1 & 100.4 \\
\hline $\mathrm{Ca}$ & 0.7 & 1.3 & 0.6 & 1.4 & 0.6 & 1.5 \\
$\mathrm{Mg}$ & 87.5 & 86.0 & 87.8 & 86.0 & 87.6 & 85.1 \\
$\mathrm{Fe}$ & 11.8 & 12.7 & 11.5 & 12.6 & 11.9 & 13.4 \\
\hline $\mathrm{K} \mathrm{D}_{\mathrm{Opx}}^{\text {ppx }}$ & & 1.09 & & & & 1.16 \\
\hline
\end{tabular}

* Total $\mathrm{Fe}$ as $\mathrm{FeO}$

Therefore, the fact that $\mathrm{K}_{\mathrm{DO}_{\mathrm{px}}^{\mathrm{Pp}}}$ is higher than unity means that the stability fields of protopyroxene and orthopyroxene in the system $\mathrm{MgSiO}_{3}-\mathrm{FeSiO}_{3}$ should be those shown in Fig. 3. It is, of course, based also on the experimental evidence that protopyroxene and orthopyroxene are higher and lower temperature polymorphs, respectively.

Dalwitz, Green \& Thompson (1966) described that the outer zones of the phenocryst crystal are more magnesian than core in both orthopyroxene and protopyroxene. They suggested that the reversed zoning resulted from either temperature rise or oxidation of the magma during the stage of phenocryst growth. It is quite unlikely, however, that 


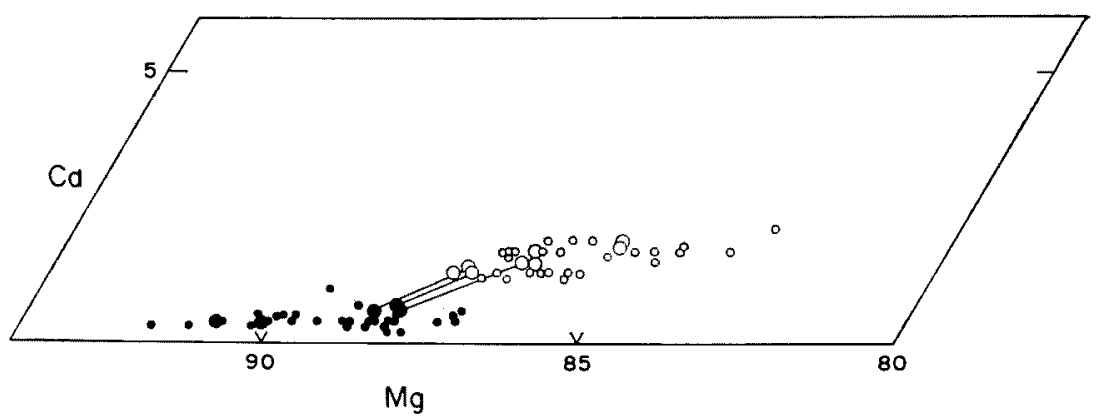

Fig. 2. Ca-Mg-Fe plot of analyzed pyroxenes. Solid circle, inverted protoenstatite; open circle, bronzite; large circle, from this paper; small circle, from Dalwitz, Green \& Thompson (1966). (?) clinoenstatite of Dalwitz, Green \& Thompson (1966) is also interpreted here as inverted protoenstatite.

temperature of magma rises during the stage of phenocryst growth, i.e., in the intratelluric stage. The apparent reversed zoning would have resulted simply from temperature fall during the stage of phenocryst growth provided that protoenstatite and bronzite crystallized in equilibrium. and the inclination of the orthopyroxene-protopyroxene inversion curve has a positive slope as shown in Fig. 3.

\section{Stablility field of Ca-poor clinopyroxene}

Since the contribution by Hess (1941), stability field of Ca-poor clinopyroxene has been discussed mostly with reference to the experimental work by Bowen \& Schairer (1935). Recently, however, some doubts have been cast on the work of Bowen and Schairer (e.g., Yoder, Tilley \& Schairer (1963)). The microprobe study by Nakamura \& Kushiro (1970b) on natural coexisting pigeonite, hypersthene and augite demonstrated that pyroxene of pigeonite composition has a stability field on the higher temperature side relative to hypersthene +augite assemblage. Nakamura \& Kushiro, however, discussed only on the stability 
field of clinopyroxene of natural pigeonite compostion $(\mathrm{Ca} /(\mathrm{Ca}+\mathrm{Mg}+\mathrm{Fe})$ $\simeq 0.1$ ) and did not refer to the stability of Ca-free clinopyroxene:

Smith (1969a) suggested that symmetry of $\mathrm{MgSiO}_{3}$ pyroxene at high temperatures would be $\mathrm{C} 2 / \mathrm{c}$. Smyth (1969) found that orthopyroxene of composition $\mathrm{Mg}_{30} \mathrm{Fe}_{70}$ transforms into clinopyroxene with $\mathrm{C} 2 / \mathrm{c}$ symmetry after heating at $1,100^{\circ} \mathrm{C}$ for 60 hours. It is thus conceivable that orthopyroxene in the system $\mathrm{MgSiO}_{3}-\mathrm{FeSiO}_{3}$ inverts to clinopyroxene with $\mathrm{C} 2 / \mathrm{c}$ symmetry at high temperatures except in the Mg-rich part, where stability field of protopyroxene would exist in between.

On the other hand, Morimoto \& Tokonami (1969) suggested, from the domain structure in pigeonites of volcanic origin $(\mathrm{Ca} / \mathrm{Ca}+\mathrm{Mg}+\mathrm{Fe})$ $\simeq 0.1$ ), that pigeonite with $\mathrm{P} 2{ }_{1} / \mathrm{c}$ symmetry once had $\mathrm{C} 2 / \mathrm{c}$ symmetry at the time of its crystallization at high temperature. Prewitt, Papike \& Ross (1970) confirmed the suggestion of Morimoto \& Tokonami by heating experiments on the $\mathrm{Ca}$-poor clinopyroxene of $\mathrm{Ca}_{4} \mathrm{Mg}_{17} \mathrm{Fe}_{78}$ composition.

The results of these investigations suggest that continuous solid solution exists between $\mathrm{Ca}$-free $\mathrm{C} 2 / \mathrm{c}$ clinopyroxene and $\mathrm{C} 2 / \mathrm{c}$ clinopyroxene with composition of $\mathrm{Ca} /(\mathrm{Ca}+\mathrm{Mg}+\mathrm{Fe}) \simeq 0.1$. There are no reasons to conceive of the presence of solvus between the two, but it would be better to interpret simply that the field of Ca-poor clinopyroxene is enlarged toward lower-temperature side with increasing $\mathrm{Ca}$ content as shown in Fig. $5 f$.

Ca-poor pigeonite was found in some Apollo 12 lunar rocks. For instance, Kushiro, Nakamura, Kitayama \& Akimoto (1971) described a low-Ca pigeonite $\left(\mathrm{Ca}_{6} \mathrm{Mg}_{68} \mathrm{Fe}_{76}\right)$ in the core of pigeonite crystal in rock 12065. They also confirmed experimentally that such $\mathrm{Ca}$-poor pigeonite crystallizes at $1,200^{\circ} \mathrm{C}$ and $1,170^{\circ} \mathrm{C}$ from synthetic liquid of composition similar to that of the rock 12065 . The temperature of crystallization of Ca-poor pigeonite in the rock 12065 would be higher than that of pigeonite in terrestrial basalt and andesite, because the rock 12065 contains less feldspar and volatile components than terrestrial basalt and 


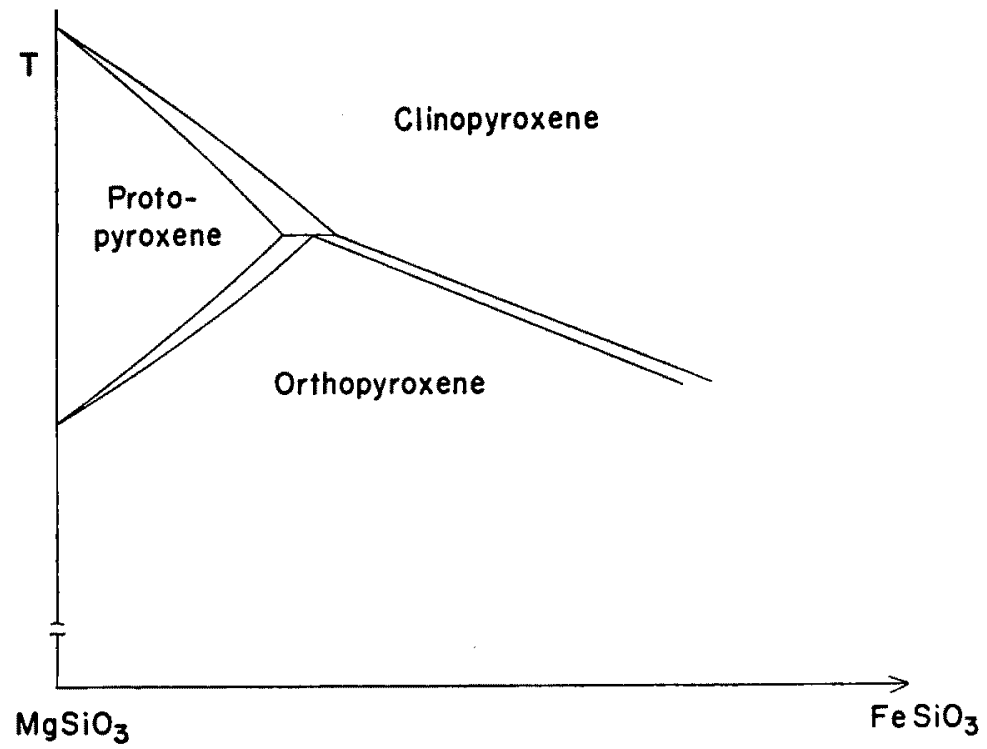

Fig. 3. Probable subsolidus phase diagram of the system $\mathrm{MgSiO}_{3}-\mathrm{FeSiO}_{3}$

andesite. The crystallization of Ca-poor pigeonite at higher temperature strongly suggests that the field of pigeonite is enlarged toward more Ca-poor region with increasing temperature, which is consistent with the present interpretation.

Partition coefficient of $\mathrm{Mg}$ and $\mathrm{Fe}$ between pigeonite and hypersthene would also be applicable to coexisting orthopyroxene and clinopyroxene in the Ca-free system if continuous solid solution exists from $\mathrm{Ca}$-free clinopyroxene to pigeonite. Change of the partition coefficient due to the change of temperature and $\mathrm{Ca}$ content would not be great at temperatures above $1,000^{\circ} \mathrm{C}$. The partition coefficient, $\mathrm{K}_{\mathrm{D}_{\mathrm{PIg}}^{\mathrm{Hyp}}}^{\mathrm{Hy}}$ $\left(\left(\frac{\mathrm{Mg}}{\mathrm{Fe}}\right)^{\mathrm{HgD}} /\left(\frac{\mathrm{Mg}}{\mathrm{Fe}}\right)^{\mathrm{PIg}}\right)$, determined by Nakamura \& Kushiro (1970b) is slightly lower than 1.1, indicating that clinopyroxene has always lower $\mathrm{Mg} / \mathrm{Fe}$ ratio than coexisting orthopyroxene. The orthopyroxene-clino- 
pyroxene inversion curve should, therefore, be that shown in Fig. 3.

The present interpretation is apparently the same as those by Hess (1941), Brown (1957) and Kuno (1950, 1966). However, it is independent of the experimental result of Bowen \& Schairer (1935). It should be also noted that stability of pyroxene of natural pigeonite composition $(\mathrm{Ca} /(\mathrm{Ca}+\mathrm{Mg}+\mathrm{Fe}) \simeq 0.1)$ must be compared relative to hypersthene+ augite as discussed by Nakamura \& Kushiro (1970b).

Kushiro (1969) synthesized Fe-free pigeonite at $20 \mathrm{~kb}$ and found that Ca-free clinopyroxene is unstable at all temperatures. Kushiro \& Yoder (1970) suggested that the similar relations would be expected in the Fe-bearing system at $1 \mathrm{~atm}$, conflicting with the present interpretation. Probably, stability field of Ca-free clinopyroxene relative to that of orthopyroxene would be reduced and shifted to higher temperature side rapidly with increasing pressure, while that of Ca-bearing clinopyroxene would be reduced less rapidly as shown by Brown (1968). Consequently, orthopyroxene-clinopyroxene inversion temperature in the Ca-free system would become higher than the solidus temperature at high pressures, while temperature at which orthopyroxene and Ca-rich clinopyroxene react to form pigeonite would remain under the solidus temperature. The composition of the Ca-poor clinopyroxene at high pressures would thus become limited to $\mathrm{Ca} /(\mathrm{Ca}+\mathrm{Mg}+\mathrm{Fe}) \simeq 0.1$, as is in Kushiro's phase diagram.

Little is known about the stability relations between protopyroxene and Ca-poor clinopyroxene. It is assumed in Fig. 3 that clinopyroxene is a higher temperature form. This is consistent with the suggestion by Smith $(1969 \mathrm{a}, \mathrm{b})$ on the basis of crystallographical studies.

Fig. 3 is essentially the same as one of the two hypothetical phase diagrams proposed by Boyd \& Schairer (1964). The present phase diagram is, however, based mainly on the $\mathrm{Mg}-\mathrm{Fe}$ paritions in the natural pyroxene assemblages, as shown above. 
Equilibrium relations in ternary system

The ternary phase equilibria is discussed here on the following three premises:

(1) Equilibrium relations in the system $\mathrm{MgSiO}_{3}-\mathrm{FeSiO}_{3}$ in Fig. 3 are true.

(2) Both $K_{D_{C a-p o o r}^{0 p x}}^{0 p x}$ and $K_{D_{0 p x}^{P p x}}^{P p a l u e s}$ approximately equal 1.1 in the temperature range concerned and $\mathrm{K}_{\mathrm{D}_{\mathrm{Ca}-\mathrm{rlch}}^{\mathrm{Opx}} \mathrm{Cpx}}$ value is $0.7 \sim 0.8$

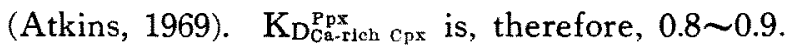

(3) Orthopyroxene is richer in $\mathrm{Ca}$ than coexisting protopyroxene, and $\mathrm{Ca}$-poor clinopyroxene is richer in $\mathrm{Ca}$ than coexisting orthopyroxene. When three $\mathrm{Ca}$-poor pyroxenes coexist, difference of $\mathrm{Ca} /(\mathrm{Ca}+\mathrm{Mg}+$ $\mathrm{Fe}$ ) between protopyroxene and orthopyroxene is smaller than that between orthopyroxene and Ca-poor clinopyroxene.

The latter half of the premise (3) is a reasonable assumption based on $\mathrm{Ca}$ contents of natural Ca-poor pyroxenes. It is deduced from (2) and (3) that composition of orthopyroxene coexisting with both protopyroxene and $\mathrm{Ca}$-poor clinopyroxene falls in the Ca-poor side of the join between protopyroxene and $\mathrm{Ca}$-poor clinopyroxene as shown in Figs. $4 \mathrm{c}$ and $4 \mathrm{~d}$. A set of isothermal sections at $1 \mathrm{~atm}$ is given in Fig. 4. Temperature decreases successively from Fig. 4a to $f$. These equilibrium relations are derived uniquely from the three premises without any further assumptions. Coexistence of four pyroxenes as shown in Fig. 4d is possible only at a fixed temperature at isobaric conditions. Compositions of four pyroxenes are also fixed to $\mathrm{k}, \mathrm{l}, \mathrm{m}$ and $\mathrm{n}$ in Fig. 4d. Fig. 5 shows selected cross sections along the lines from $\mathrm{CaSiO}_{3}$ apex to the join $\mathrm{MgSiO}_{3}-\mathrm{FeSiO}_{3}$ of variable $\mathrm{Mg} / \mathrm{Fe}$ ratios. Such diagrams will be of use for experimental studies expected in the future. Fig. $5 \mathrm{a}, \mathrm{b}, \mathrm{c}$ and $\mathrm{d}$ show cross sections along the lines passing isobaric invariant points $\mathrm{k}, \mathrm{l}, \mathrm{m}$ and $\mathrm{n}$, respectively. Fig. $5 \mathrm{e}$ and $\mathrm{f}$ show those of more ferriferous parts.

As far as subsolidus relations are concerned, the proposed equilibrium relations summarized in Fig. 4 can explain compositional relations 

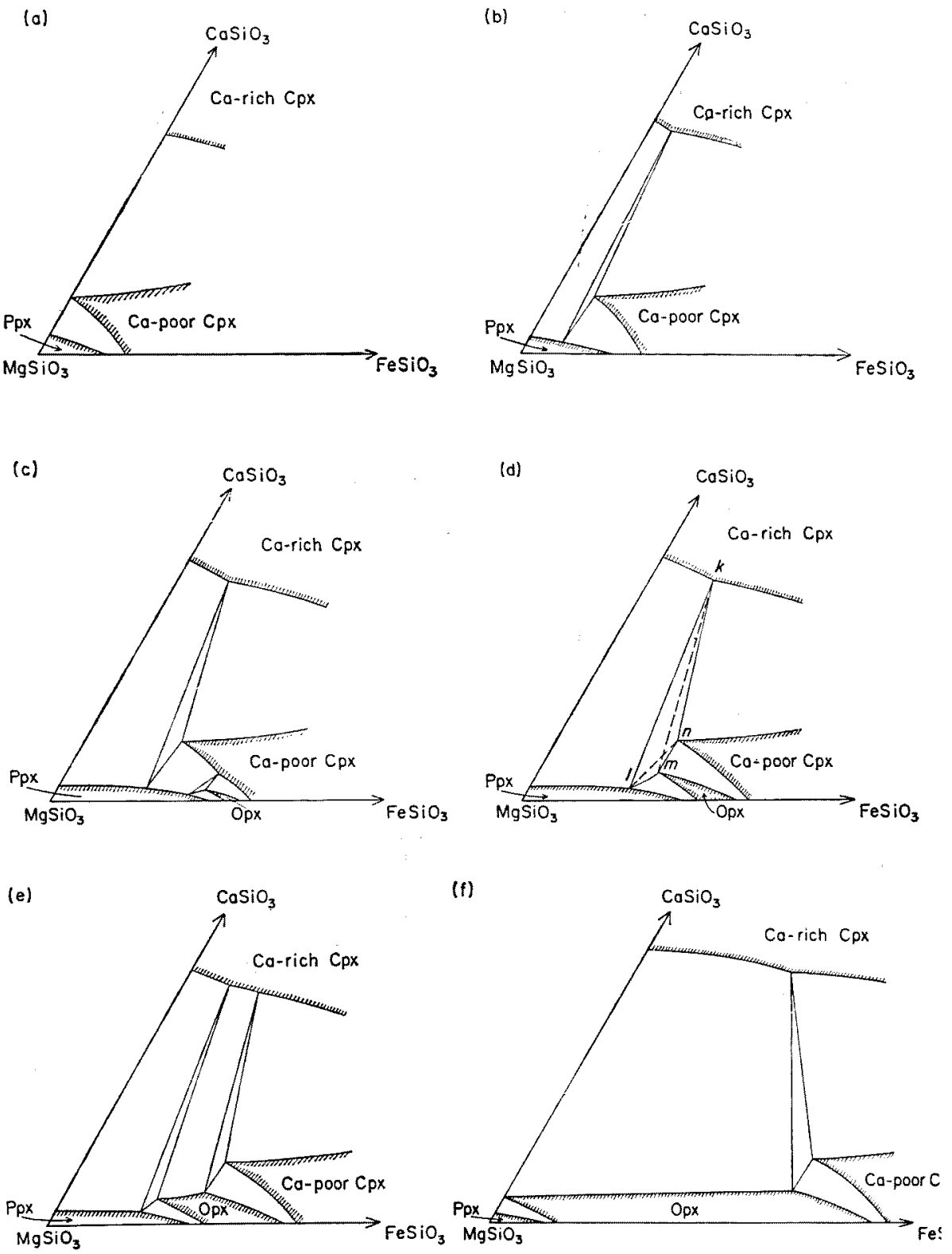

Fig. 4. Probable isothermal sections in the Mg-rich part of the system $\mathrm{CaSiO}_{8}-\mathrm{MgSiO}_{8}-\mathrm{FeSiO}_{3}$. Temperature falls successively from a to $\mathrm{f}$. 

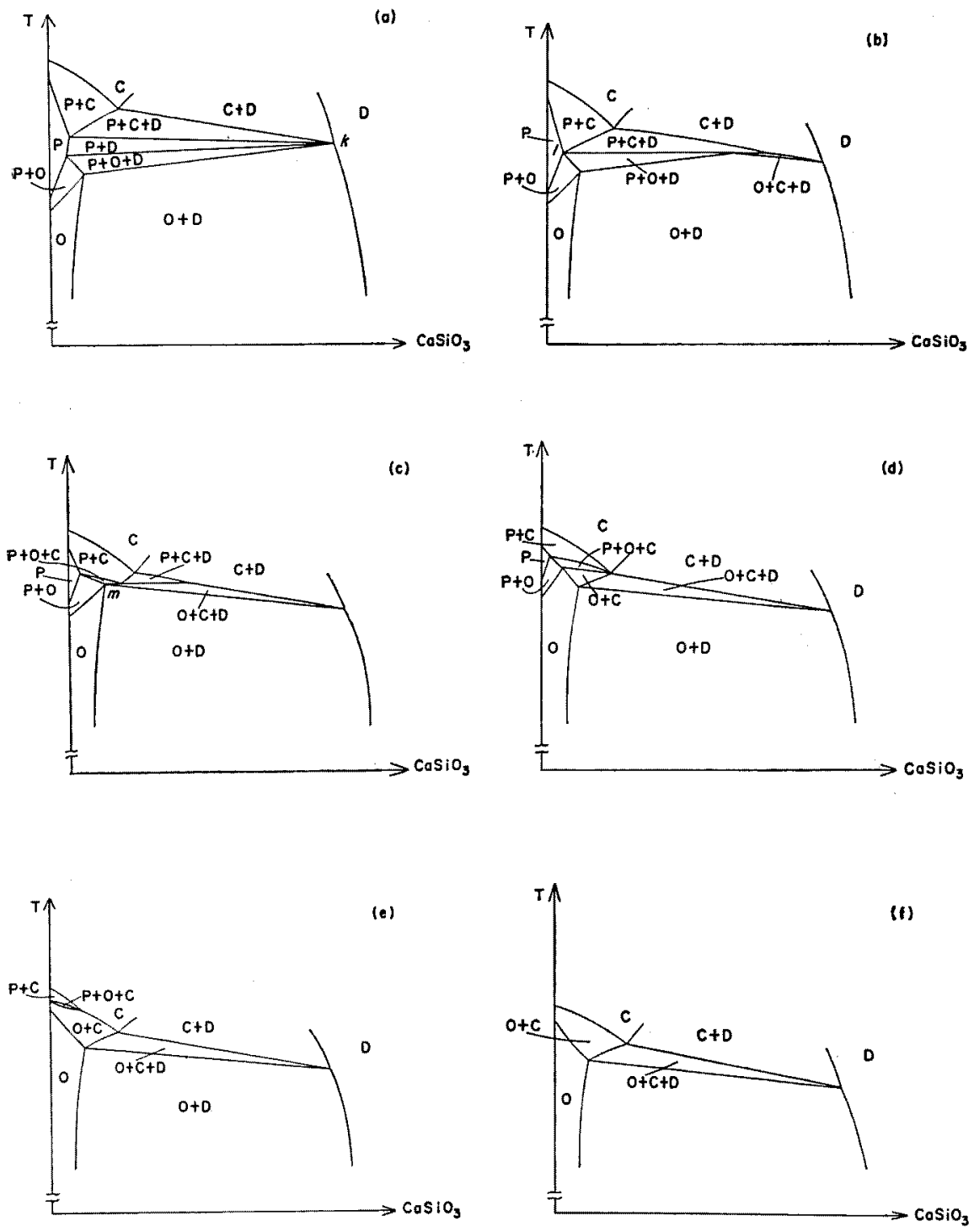

Fig. 5. Cross sections along the lines from $\mathrm{CaSiO}_{3}$ apex to the join $\mathrm{MgSiO}_{3}-\mathrm{FeSiO}_{3}$ of variable $\mathrm{Mg} / \mathrm{Fe}$ ratios. $\mathrm{Mg} / \mathrm{Fe}$ ratio decreases successively from a to $\mathrm{f}$. a, b, c, d are cross' sections passing k, l, m, n of Fig. 4d, respectively. $\mathrm{P}$, protopyroxene; $\mathrm{O}$, orthopyroxene; $\mathrm{C}$, Ca-poor clinopyroxene; $\mathrm{D}$, Ca-rich clinopyroxene. 
of pyroxenes from igneous rocks of various occurrences, e.g., protopyroxene, orthopyroxene, pigeonite and augite from Cape Vogel (Dalwitz, Green \& Thompson, 1966), orthopyroxene, pigeonite and augite from Skaergaard (Brown, 1957), Bushveld (Atkins, 1969), Weiselberg (Nakamura \& Kushiro, 1970b) and many volcanic rocks (Kuno, 1966).

\section{Acknowledgement}

The writer wishes to thank Dr. I. Kushiro and Dr. F. P. Okamura (University of Tokyo) for discussion. He is indebted to Dr. I. Kushiro and Dr. N. Shimizu (University of Tokyo) for critical reading of manuscript.

\section{References}

Atkins, F.B. (1969). J. Petrol. 10, 222.

Atlas, L. (1952). J. Geol. 60, 125.

Bowen, N. L. \& Schairer, J. F. (1935). Amer. J. Sci. 229. 151.

Boyd, F. R. \& Schairer, J. F. (1964). J. Petrol. 5, 275.

Brown, G. M. (1957). Miner. Mag. 31, 511.

-(1968). Carnegie Inst. Wash. Year Book, 66, 285.

Dalwitz, W. B., Green, D. H. \& Thompson, J. E. (1966). J. Petrol. 7, 375.

Hess, H. H. (1941). Amer. Min. 26, 515 \& 573.

Kuno, H. (1950). Bull. Geol. Soc. Amer. 61, 957.

-(1966). Miner. J. 5, 21.

Kushiro, I. (1969). Amer. J. Sci. 267, 269.

Kushiro, I. \& Yoder, H. S. Jr. (1970). Carnegie Inst. Wash.Year Book. 68, 226.

Kushiro, I. \& Nakamura, Y. (1970). Proc. Apollo 11 Lunar Science Conference, 1,607 .

Kushiro, I., Nakamura, Y., Kitayama, K. \& Akimoto, S. (1971). Proc. Apollo

12 Lunar Science Conference (in press).

Morimoto, N. \& Tokonami, M. (1969). Amer. Min. 54, 725.

Nakamura, Y. \& Kushiro, I. (1970a). Contr. Miner. Petrol. 26, 265. (1970b). Amer. Min. 55, 1999.

Prewitt, C. T., Papike, J. J. \& Ross, M. (1970). Amer. Min. 55, 305.

Sadanaga, R. \& Okamura, F. P. (1969). Proc. Japan Acad. 45, 721.

Sмiтн, J. V. (1969a). Nature. 222, 256.

- (1969b). Miner. Soc. Amer. Spec. Paper, 2, 3.

SMYTH, J. R. (1969). Earth Planet. Sci. Letters, 6, 406. 
Yoder, H.S. Jr., Tilley, C. E. \& Schairer, J. F. (1963). Carnegie Inst. Wash. Year Book, 62, 84.

Manuscript received 5 February 1971. 